\title{
ПРЕЭКЛАМПСИЯ У КОРОВ: ФУНКЦИОНАЛЬНЫЕ НАРУШЕНИЯ В СИСТЕМЕ МАТЬ-ПЛАЦЕНТА-ПЛОД И ИХ ПОСЛЕДСТВИЯ ДЛЯ ЗДОРОВЬЯ ПОТОМСТВА
}

\author{
А.Е. ЧЕРНИЦКИЙ 1 , С.В. ШАБУНИН 1 , В.А. САФОНОВ 2
}

Научный интерес к таким патологиям беременности, как функциональная недостаточность фетоплацентарной системы, внутриутробная задержка развития эмбриона и плода и преэклампсия (гестоз), обусловлен их широким распространением среди продуктивных животных и негативным влиянием на постнатальный рост и здоровье потомства. В настоящей работе впервые показана диагностическая ценность маркеров эндогенной интоксикации, нефропатии, нарушений фетоплацентарного кровообращения и эндокринной функции плаценты у коров, больных преэклампсией, для прогнозирования неонатальных заболеваний у их потомства. Целью работы было изучение влияния морфофункциональных нарушений у коров, больных преэклампсией, на заболеваемость новорожденных телят анемией, омфалитом, воспалительными заболеваниями желудочно-кишечного и респираторного тракта, а также интенсивность роста в первые 2 мес жизни. Исследование проводили в 2016 году в условиях крупного молочного комплекса (ООО «Воронежпищепродукт», Новоусманский р-н, Воронежская обл.) на коровах (Bos taurus taurus) краснопестрой породы. Всего были обследованы 45 коров со сроком беременности 248-255 сут, в том числе 31 с клиническими признаками преэклампсии (I группа) и 14 с физиологическим течением беременности (II группа), а также полученные от них телята $(n=45)$. У коров оценивали наличие клинических признаков преэклампсии (патологические отеки молочной железы, вентральной брюшной стенки, подгрудка, тазовых конечностей, артериальная гипертензия и протеинурия), определяли конщентрацию прогестерона, эстрадиола и дегидроэпиандростерон-сульфата (ДГЭАС) в сыворотке крови, исследовали показатели эндогенной интоксикации - концентрацию среднемолекулярных пептидов (СМП), эффективную (ЭКА) и общую (ОКА) конщентрацию альбумина в сыворотке крови, рассчитывали индекс токсичности ИТ $=($ ОКА/ЭКА $)-1$ и коэффициент интоксикации КИ $=($ СМП/ЭКА $) \times 1000$. В течение $1-3$ ч после рождения у телят измеряли диаметр пупка. Если он имел размер более 18,0 мм, это рассматривали как ретроспективный показатель нарушений фетоплацентарного кровообращения. На 1-е, 30-е и 60-е сут измеряли массу тела телят, рассчитывали ее абсолютный, относительный и среднесуточный прирост за 1-й и 2-й мес жизни. В течение первых 60 сут жизни за телятами вели постоянное клиническое наблюдение, учитывали заболеваемость анемией, омфалитом, гастроэнтеритом, бронхитом, бронхопневмонией и тяжесть их течения. У телят, полученных от коров с преэклампсией, анемию регистрировали чаще в 1,80 раза, омфалит - в 9,40 раза, гастроэнтерит - в 1,80 раза, бронхит в 1,75 раза, бронхопневмонию - в 2,71 раза по сравнению с потомством животных с физиологическим течением беременности. Среднесуточный прирост массы тела за 1-й мес жизни у телят от коров из I группы был на $46,2 \%(p<0,01)$ меньше, чем у потомства здоровых животных. Среди коров с симптомами преэклампсии обнаружены значительные межиндивидуальные различия по концентрации белка в моче, показателям эндогенной интоксикации (ЭКА/ОКА, СМП, КИ) и содержанию стероидных гормонов (прогестерон, эстрадиол, ДГЭА-С) в сыворотке крови. Установлена обратная зависимость между коэффициентом интоксикации у коров из I группы и среднесуточным приростом массы тела у полученных от них телят за 1 -й $\left(r_{S}=-0,79\right.$ при р $\left.<0,01\right)$ и 2 -й мес жизни $\left(r_{S}=-0,58\right.$ при р $\left.<0,01\right)$. С повышением протеинурии у коров возрастала вероятность развития омфалита $\left(r_{\tau-K}=+0,32\right.$ при р $\left.<0,05\right)$ и анемии $\left(r_{\tau-K}=+0,33\right.$ при р $\left.<0,05\right)$ у телят. Статистически значимую зависимость обнаружили между накоплением СМП в крови у коров из I группы и вероятностью развития омфалита $\left(r_{\tau-K}=+0,36\right.$ при р $\left.<0,01\right)$ и бронхопневмонии $\left(r_{\tau-K}=+0,35\right.$ при р $\left.<0,05\right)$ у их потомства, а также между коэффициентом интоксикации и вероятностью развития этих заболеваний (коэффициенты $\tau$-Кендалла соответственно $+0,35$ и $+0,38$ при $p<0,05)$. С функциональной недостаточностью фетоплацентарной системы было связано развитие у телят омфалита $\left(r_{\tau-K}=+0,33\right.$ при $\left.\mathbf{p}<0,05\right)$ и гастроэнтерита $\left(r_{\tau-K}=+0,49\right.$ при р $\left.<0,01\right)$, а также ранняя (в 1-ю нед жизни) манифестация бронхита $\left(r_{\tau-K}=+0,48\right.$ при $\mathbf{p}<0,01)$, с нарушением фетоплацентарного кровообращения - развитие гастроэнтерита $\left(r_{\tau-K}=+0,77\right.$ при р $\left.<0,01\right)$ и бронхопневмонии $\left(r_{\tau-K}=+0,75\right.$ при p $\left.<0,01\right)$. ROC-анализ показал, что коэффициент интоксикации и содержание СМП в сыворотке крови коров, больных преэклампсией, могут служить предикторами развития омфалита и бронхопневмонии у новорожденных телят. Для прогнозирования тяжелого течения гастроэнтерита и анемии у телят высокую ценность показало определение концентрации эстрадиола и соотношения прогестерон/эстрадиол в сыворотке крови коров. Высокая специфичность $(94,7$ \%) для прогнозирования развития анемии у новорожденных телят была обнаружена для протеинурии более 2,0 г/л.

Ключевые слова: преэклампсия, беременность, Bos taurus taurus, коровы, телята, артериальная гипертензия, протеинурия, анемия, омфалит, гастроэнтерит, респираторные заболева- 
ния, среднесуточный прирост массы тела, ROC-анализ.

Преэклампсия (гестоз) - патологическое состояние беременных коров и нетелей, проявляющееся синдромом полиорганной функциональной недостаточности, системным эндотелиозом, нарушением маточноплацентарного и фетоплацентарного кровообращения, эндогенной интоксикацией и дезинтеграцией гормонального статуса матери и плода (1-4). По данным А.Ф. Колчиной (4), на 32-36-й нед беременности преэклампсия диагностируется у 42,0-69,4\% коров и нетелей.

Несмотря на значительный интерес к проблеме, патогенез преэклампсии у коров остается малоизученным $(1,4,5)$. В медицине считается (6-8), что преэклампсия развивается в результате воздействия на организм беременной женщины ряда нейрогенных, гормональных, иммунологических, плацентарных и генетических факторов. Заболевание развивается в два этапа (7). На первом этапе нарушаются инвазия трофобласта и ремоделирование спиральных артерий в эндометрии, наблюдается сосудистый спазм, снижается маточно-плацентарная перфузия (6). На втором этапе развиваются синдром системного воспалительного ответа и полиорганная недостаточность $(6,8)$. Многочисленные попытки экспериментального воспроизведения преэклампсии у лабораторных животных не увенчались успехом (9). При перевязке сосудов, питающих матку, у беременных крыс, кроликов и обезьян удавалось вызвать ишемию плаценты и задержку роста плодов, однако характерные для преэклампсии изменения реологических и коагуляционных свойств крови, нарушения микроциркуляции и артериальная гипертензия не развивались (9).

У молочных коров выделяют две группы причин, приводящих к развитию преэклампсии. Первая связана с наличием экстрагенитальной патологии (гепато- и нефропатии), сопровождаемой эндогенной интоксикацией, нарушениями метаболического (изменения белкового и липидного состава крови, развитие оксидативного стресса) и иммунного статуса (активация системы комплемента и лизоцима), повышением агрегации эритроцитов и тромбоцитов, изменением реологических и коагуляционных свойств крови, нарушением микроциркуляции с повреждением эндотелия капилляров, особенно в тканях формирующейся плаценты $(1,5,10)$. Вторая группа причин связана с эндокринной недостаточностью, приводящей к нарушению маточно-плацентарного кровообращения и диффузно-перфузионной недостаточности плаценты $(4,10)$. По мнению А.Г. Нежданова и соавт. (10), на начальном этапе развития преэклампсии негативные факторы могут накладываться друг на друга и создавать кумулятивный эффект.

Классические признаки преэклампсии у коров - артериальная гипертензия, протеинурия (нефропатия), патологические отеки молочной железы, вентральной брюшной стенки, подгрудка и тазовых конечностей $(1,4,10)$. Перечисленные симптомы могут проявляться у животных как по отдельности, так и в различных сочетаниях пропорционально тяжести заболевания $(2,4,10)$. По данным А.Ф. Колчиной (4), у 35,3 \% коров и нетелей, больных преэклампсией, регистрируются отеки, у 4,7 \% нефропатии, у 40,2 \% - полисистемные формы. Для заболевания характерна функциональная недостаточность системы антиоксидантной защиты и фетоплацентарного комплекса (4).

Морфологические исследования материнской и плодной частей плаценты у коров с преэклампсией $(4,11)$ выявили глубокие сосудистые изменения с элементами застойной гиперемии, наличием кровоизлияний, экстравазатов и дистрофическими явлениями. У телят, полученных от та- 
ких коров, пупочные сосуды кровенаполненные, с увеличенным просветом и диаметром, местами разрыхленным и прерывистым эндотелием интимы, кровенаполненными сосудами мышечной оболочки, редко расположенными миоцитами и вакуолями между ними, увеличенными и разрыхленными коллагеновыми волокнами адвентиции (12).

Описанные морфофункциональные нарушения у беременных животных сопровождаются существенными изменениями в обмене веществ $(1,4)$, структуре и функциональном состоянии органов и систем плода $(2)$, что приводит к рождению потомства с пониженной жизнеспособностью $(4,12,13)$, недоразвитыми на клеточном и субклеточном уровне органами и системами (14-17), с низкими показателями естественной резистентности $(2,12)$ и адаптационными возможностями $(15,18,19)$.

В настоящей работе впервые показана диагностическая ценность определения маркеров эндогенной интоксикации, нефропатии, нарушений фетоплацентарного кровообращения и эндокринной функции плаценты у коров, больных преэклампсией, для прогнозирования неонатальных заболеваний у их потомства. Обнаружена зависимость между тяжестью эндогенной интоксикации у коров, больных преэклампсией, и среднесуточным приростом массы тела у полученных от них телят за 1-й и 2-й мес жизни, а также вероятностью развития омфалита и бронхопневмонии. Показана связь функциональной недостаточности фетоплацентарной системы у коров с развитием омфалита, гастроэнтерита и ранней (в 1-ю нед жизни) манифестацией бронхита у телят, а также нарушений фетоплацентарного кровообращения - с развитием гастроэнтерита и бронхопневмонии у потомства. Установлено, что с повышением концентрации белка в моче у коровматерей возрастает вероятность развития анемии у новорожденных телят.

Нашей целью было изучение влияния морфофункциональных нарушений у коров, больных преэклампсией, на заболеваемость новорожденных телят анемией, омфалитом, воспалительными заболеваниями желудочно-кишечного и респираторного тракта, а также интенсивность роста в первые 2 мес жизни.

Методика. Исследования выполняли в зимне-стойловый период 2016 года в производственных условиях ООО «Воронежпищепродукт» (Новоусманский р-н, Воронежскоая обл.). Всего обследовали 45 коров (Bos taurus taurus) красно-пестрой породы со сроком беременности 248255 сут, в том числе 31 корову с клиническими признаками преэклампсии (I группа) и 14 животных с физиологическим течением беременности (II группа), а также полученных от них телята $(n=45)$. Молочная продуктивность коров за предыдущую лактацию составила 6278-9796 кг, жирность молока - 3,54-3,96\%.

При клиническом исследовании у коров оценивали габитус, упитанность, наличие отеков молочной железы, вентральной брюшной стенки, подгрудка, тазовых конечностей, определяли ректальную температуру, частоту сердечных сокращений (ЧСС) и дыхательных движений (ЧДД) в минуту, систолическое (сАКД) и диастолическое (дАКД) артериальное кровяное давление. Учитывали характер течения родов (нормальное, родовспоможение и причины). В течение 1-3 ч после рождения у телят измеряли диаметр пупка у его основания. Увеличение диаметра пупка более 18,0 мм рассматривали в качестве ретроспективного показателя нарушений фетоплацентарного кровообращения (12).

На 1-е, 30-е и 60-е сут после рождения телят взвешивали, рассчитывали абсолютный, относительный и среднесуточный прирост живой массы за 1-й и 2-й мес жизни. В течение первых 60 сут за телятами вели 
постоянное клиническое наблюдение, определяли ректальную температуру, ЧСС и ЧДД в минуту, состояние видимых слизистых оболочек, аппетит, чувствительность гортани, трахеи и межреберных промежутков при пальпации, время появления и характер кашля, хрипов, одышки, носовых истечений, выделений из глаз. Показатели легочной вентиляции (дыхательный объем и минутный объем дыхания) исследовали с помощью спирометра ССП (КПО «Медаппаратура», Украина) и маски с системой клапанов. При диагностике омфалита обращали внимание на наличие отека в пупочной области, нижней и боковой стенке живота, утолщение пупочного канатика и пупка, покраснение кожи у основания пупка, консистенцию и цвет культи пуповины, болезненность пупка, пупочного кольца, местное повышение температуры тела. О наличии воспалительного процесса в кишечнике у телят судили по наличию в кале растворимого белка, гемоглобина, лейкоцитов и сдвига рН в кислую (менее 7,0) или щелочную (более $7,5)$ сторону (20). При диарейном синдроме обращали внимание на частоту дефекации, цвет, запах, консистенция фекалий, тургор кожи, западение глазных яблок, тонус сфинктера ануса, болезненность брюшной стенки при пальпации. Состояние телят при респираторном синдроме оценивали в баллах по системе WI (21), учитывали время появления первых клинических признаков и разгара бронхита, тяжесть течения болезни, осложнение в виде бронхопневмонии.

Кровь для лабораторных исследований у коров брали за 30 сут до предполагаемого отела, у телят - через 24 ч после рождения из яремной вены с помощью коммерческих вакуумных систем для забора крови, в качестве антикоагулянта использовали EDTA. Сыворотку получали центрифугированием крови (без добавления антикоагулянта) 4000 об/мин при (UC-1612, «ULAB», Китай) и комнатной температуре в течение 10 мин. Образцы сыворотки замораживали и хранили в жидком азоте при $-196{ }^{\circ} \mathrm{C}$ до проведения биохимических исследований.

Образцы мочи у коров собирали в стерильные полипропиленовые контейнеры за 30 сут до предполагаемого отела. Концентрацию белка в моче определяли на автоматическом анализаторе PocketChem PU-4210 («Arkrey», Япония).

Гематологические исследования проводили на анализаторе Micros60 («Horiba ABX», Франция), лейкограмму рассчитывали стандартным методом после окраски мазков крови по Романовскому. Концентрацию прогестерона, эстрадиола и дегидроэпиандростерон-сульфата (ДГЭА-С) в сыворотке крови коров определяли методом твердофазного иммуноферментного анализа (ИФА) на анализаторе Униплан АИФР-01 (ЗАО «Пикон», Россия) с использованием коммерческих наборов производства $3 \mathrm{AO}$ «НВ Иммунотех» (Россия). Содержание среднемолекулярных пептидов (СМП) в сыворотке крови определяли на спектрофотометре Shimadzu UV-1700 («Shimadzu», Япония) по разработанной нами методике (22). Эффективную (ЭКА) и общую концентрацию альбумина (ОКА) в сыворотке крови измеряли с помощью наборов производства НИИ Физико-химической медицины (Россия) на спектрофлуорофотометре Shimadzu RF-5301 PC («Shimadzu», Япония).

Интегральные показатели эндогенной интоксикации рассчитывали по следующим формулам (23):

Индекс токсичности (ИТ) $=($ ОКА/ЭКА $)-1$,

Коэффициент интоксикации $($ КИ $)=($ СМП/ЭКА $) \times 1000$.

Тяжесть течения заболеваний оценивали в баллах: 0 - отсутствие заболевания, 1 - легкое течение, 2 - умеренно-тяжелое течение и 3 - 
тяжелое течение. Диагностическую ценность маркеров эндогенной интоксикации, нефропатии, нарушений фетоплацентарного кровообращения и эндокринной функции плаценты у коров, больных преэклампсией, для прогнозирования неонатальных заболеваний (анемии, омфалита, гастроэнтерита и бронхопневмонии) у их потомства определяли с использованием ROC-анализа по методу E.R. DeLong и соавт. (24). Анализировали параметры ROC-кривой, в частности AUC (area under curve, площадь под кривой; характеризует диагностическую ценность показателя: 0,9-1,0 отличная; 0,8-0,9 - очень хорошая; 0,7-0,8 - хорошая, 0,6-0,7 - средняя, от 0,6 и меньше - неудовлетворительная), чувствительность (\%), специфичность (\%) и критические значения («cut-off point»).

Статистическую обработку данных выполняли с использованием программ Statistica 8.0 («StatSoft Inc.», США) и IBM SPSS Statistics 20.0.0.1 («IBM Corp.», США). Вычисляли средние арифметические и стандартные отклонения $(M \pm \mathrm{SD})$, минимальное $(\min )$, максимальное значения (max) и медиану $(M e)$. Поскольку распределение большей части показателей не подчинялось нормальному закону (W-тест Шапиро-Уилка), достоверность различий между группами определяли, сравнивая медианы с использованием непараметрического критерия Вилкоксона. Взаимосвязь между показателями выявляли с помощью непараметрических критериев корреляции Спирмена $\left(r_{S}\right)$ и $\tau$-Кендалла $\left(r_{\tau-K}\right)$. Нулевая гипотеза при применении всех методов статистической обработки отвергалась при $\mathrm{p}<0,05$.

Результаты. При клиническом исследовании у коров с преэклампсией мы установили повышение частоты сердечных сокращений $(96,8 \pm 5,5$; $M e=98,0)$ и дыхательных движений $(26,7 \pm 4,2 ; M e=26,0)$ в минуту соответственно на 45,2 (p $<0,01)$ и 44,4 \% (p < 0,05) по сравнению с теми же показателями в группе с физиологическим течением беременности. Систолическое артериальное кровяное давление находилось в пределах 120,0152,0 мм рт. ст. $(M e=138,0$ мм рт. ст.), диастолическое $-92,0-112,0$ мм рт. ст. $(M e=96,0$ мм рт. ст.), что оказалось выше медианных значений у коров из II группы на 30,2 (p $<0,01)$ и $52,4 \%$ (p $<0,01)$. Патологические отеки вентральной брюшной стенки, подгрудка и тазовых конечностей наблюдали у 80,6 \% коров с артериальной гипертензией.

Среди животных с симптомами преэклампсии обнаружили значительные межиндивидуальные различия по концентрации белка в моче, показателям эндогенной интоксикации (ЭКА/ОКА, СМП, КИ) и содержанию стероидных гормонов в сыворотке крови (табл. 1). Концентрация белка в моче у коров из I группы составляла от 1,0 до 3,0 г/л $(M e=1,0$ г/л), у коров из II группы - от 0,0 до 0,3 г/л (Me=0,0 г/л). С повышением протеинурии у коров возрастала вероятность развития омфалита $\left(r_{\tau-K}=+0,32\right.$ при $\mathrm{p}<0,05)$ и анемии $\left(r_{\tau-K}=+0,33\right.$ при $\left.\mathrm{p}<0,05\right)$ у их потомства.

Достоверных различий по общей и эффективной концентрации альбумина, а также соотношению ЭКА/ОКА в сыворотке крови между группами коров не выявили. Концентрация среднемолекулярных пептидов в сыворотке крови $(0,55 \pm 0,16$ усл. ед.; $M e=0,55)$ и коэффициент интоксикации $(23,4 \pm 7,4$ усл. ед.; $M e=22,5)$ у коров с преэклампсией были выше медианных значений у животных с физиологическим течением беременности соответственно на 71,9 (р < 0,05) и 67,9 \% (p < 0,05) и значительно варьировали внутри выборки. Корреляционный анализ выявил статистически значимые зависимости между накоплением среднемолекулярных пептидов в сыворотке крови у коров из I группы и вероятностью развития омфалита $\left(\mathrm{r}_{\tau-K}=+0,36\right.$ при $\left.\mathrm{p}<0,01\right)$ и бронхопневмонии $\left(r_{\tau-K}=+0,35\right.$ при $\mathrm{p}<0,05)$ у их потомства, а также между коэффициентом интокси- 
кации и вероятностью развития указанных заболеваний (коэффициенты $\tau$-Кендалла соответственно $+0,35$ и $+0,38$ при $\mathrm{p}<0,05)$.

1. Клинические и лабораторные маркеры преэклампсии у коров красно-пестрой породы (Новоусманский р-н, Воронежская обл., 2016 год)

\begin{tabular}{|c|c|c|c|}
\hline Показатель & $M \pm \mathrm{SD}$ & $\min -\max$ & $M e$ \\
\hline \multirow{2}{*}{ ЧДД, в мин } & $\underline{26,7 \pm 4,2}$ & $26,0-32,0$ & $\underline{26,0^{*}}$ \\
\hline & $18,9 \pm 2,0$ & $16,0-22,0$ & $\overline{18,0}$ \\
\hline \multirow{3}{*}{ ЧСС, в мин } & $\underline{96,8 \pm 5,5}$ & $\underline{86,0-104,0}$ & $98,0^{* *}$ \\
\hline & $68,5 \pm 5,3$ & $60,0-75,0$ & 67,5 \\
\hline & $\underline{139,9 \pm 10,0}$ & $120,0-152,0$ & $138,0^{* *}$ \\
\hline \multirow[t]{2}{*}{ сАКД, мм рт. ст. } & $105,2 \pm 6,8$ & $95,0-112,0$ & 106,0 \\
\hline & $100,8 \pm 7,3$ & $92,0-112,0$ & $\underline{96,0 * *}$ \\
\hline дАКД, мм рт. ст. & $65,4 \pm 8,7$ & $56,0-78,0$ & 63,0 \\
\hline \multirow{2}{*}{ Протеинурия, г/л } & $\underline{1,7 \pm 0,9}$ & $\underline{1,0-3,0}$ & $\underline{1,0 * * *}$ \\
\hline & $\overline{0,1 \pm 0,1}$ & $\overline{0,0-0,3}$ & 0,0 \\
\hline \multirow{2}{*}{ ЭКА, г/л } & $\underline{23,1 \pm 4,2}$ & $\underline{14,8-30,2}$ & 23,7 \\
\hline & $26,1 \pm 4,6$ & $18,3-36,0$ & 24,9 \\
\hline \multirow{2}{*}{ ОКА, г/л } & $\underline{37,0 \pm 5,0}$ & $27,5-48,9$ & $\underline{37,0}$ \\
\hline & $\overline{39,3 \pm 4,2}$ & $33,3-48,3$ & 38,1 \\
\hline \multirow{2}{*}{ ЭКА/ОКА, \% } & $\underline{62,2 \pm 6,3}$ & $\underline{53,7-74,9}$ & 60,8 \\
\hline & $\overline{66,5 \pm 10,2}$ & $\overline{54,7-93,7}$ & $\overline{63,0}$ \\
\hline \multirow{2}{*}{ СМП, усл. ед. } & $\underline{0,55 \pm 0,16}$ & $\underline{0,30-0,78}$ & $\underline{0,55^{*}}$ \\
\hline & $0,35 \pm 0,11$ & $0,23-0,56$ & 0,32 \\
\hline \multirow{2}{*}{ КИ } & $23,4 \pm 7,4$ & $11,1-33,9$ & $\underline{22,5^{*}}$ \\
\hline & $13,5 \pm 4,0$ & $7,2-19,4$ & 13,4 \\
\hline \multirow{2}{*}{ Прогестерон, нмоль/л } & $\underline{47,7 \pm 13,8}$ & $21,6-82,4$ & $\underline{43,6^{*}}$ \\
\hline & $67,3 \pm 22,2$ & $50,7-110,7$ & 52,5 \\
\hline \multirow{2}{*}{ Эстрадиол, пмоль/л } & $\underline{96,8 \pm 53,4}$ & $\underline{32,4-245,1}$ & $\underline{90,4 * * *}$ \\
\hline & $4 \overline{35,9 \pm 114,1}$ & $24 \overline{45,1-582,9}$ & $4 \overline{43,1}$ \\
\hline \multirow{2}{*}{ ДГЭА-С, мкмоль/л } & $\underline{0,31 \pm 0,14}$ & $\underline{0,11-0,46}$ & $\underline{0,30 *}$ \\
\hline & $0,49 \pm 0,23$ & $0,14-0,85$ & 0,63 \\
\hline
\end{tabular}

П р и м е ч а и е. Над чертой - группа коров с преэклампсией $(n=31)$, под чертой - группа коров с физиологическим течением беременности $(n=14)$. ЧДД - частота дыхательных движений, ЧСС - частота сердечных сокращений, сАКД - систолическое артериальное кровяное давление, дАКД - диастолическое артериальное кровяное давление, ЭКА - эффективная концентрация альбумина, ОКА - общая концентрация альбумина, СМП - среднемолекулярные пептиды, КИ - коэффициент интоксикации, ДГЭА-С - дегидроэпиандростерон-сульфат.

*, ** и *** Различия между группами статистически достоверны соответственно при р $<0,05, \mathrm{p}<0,01$ и $\mathrm{p}<0,001$.

Содержание прогестерона $(47,7 \pm 13,8$ нмоль/л; $M e=43,6$ нмоль/л), эстрадиола $(96,8 \pm 53,4$ пмоль/л; $М е=90,4$ пмоль/л) и ДГЭА-С $(0,31 \pm 0,14$ мкмоль/л; $M e=0,30$ мкмоль/л) в сыворотке крови у коров из I группы было на 17,0 (p < 0,05), 79,6 (p < 0,001) и 52,4 \% (p < 0,05) ниже по сравнению со II группой. Функциональную недостаточность фетоплацентарной системы выявили у 71,0 \% коров с преэклампсией. С функциональной недостаточностью фетоплацентарной системы у животных из I группы было связано развитие у их потомства омфалита $\left(r_{\tau-K}=+0,33\right.$ при р $\left.<0,05\right)$ и гастроэнтерита $\left(r_{\tau-K}=+0,49\right.$ при р $\left.<0,01\right)$, а также ранняя (в $1-ю$ нед жизни) манифестация бронхита $\left(r_{\tau-K}=+0,48\right.$ при р $\left.<0,01\right)$.

У телят от коров с преэклампсией диаметр пупка составлял 17,021,0 мм $(18,4 \pm 1,1 \mathrm{мм} ; M e=18,0$ мм $)$, что на 33,3\% (p<0,01) больше, чем у потомства животных с физиологическим течением беременности - 13,016,0 мм (13,9 \pm 1,1 мм; Me=13,5 мм). У 38,9 \% телят он был более 18,0 мм, что указывало на перинатальное нарушение фетоплацентарного кровообращения (7). Мы обнаружили статистически значимую зависимость между нарушением фетоплацентарного кровообращения у коров из I группы и вероятностью развития гастроэнтерита $\left(r_{\tau-K}=+0,77\right.$ при р $\left.<0,01\right)$ и бронхопневмонии $\left(r_{\tau-K}=+0,75\right.$ при р $\left.<0,01\right)$ у их потомства. Коэффициенты ранговой корреляции Спирмена между диаметром пупка у телят в первые 3 ч после рождения и тяжестью течения гастроэнтерита и бронхопневмонии составили соответственно $+0,82$ и $+0,72$ при $\mathrm{p}<0,01$.

У телят, полученных от коров из I группы, омфалит регистрирова- 
ли чаще в 9,40 раза, гастроэнтерит - в 1,80 раза, бронхит - в 1,75 раза, бронхопневмонию - в 2,71 раза, анемию - в 1,80 раза по сравнению с потомством коров во II группе (табл. 2). В группе телят от коров с преэклампсией тяжелое течение омфалита наблюдали в 38,7 \% случаев, анемии (с содержанием гемоглобина в крови менее 70 г/л) - в 9,7 \% случаев, при физиологическом течении беременности таких осложнений не регистрировали.

2. Частота неонатальных заболеваний у телят, полученных от коров краснопестрой породы с физиологическим течением беременности и преэклампсией (Новоусманский р-н, Воронежская обл., 2016 год)

\begin{tabular}{lcc}
\hline \multicolumn{1}{c}{ Показатель } & Физиологическое течение беременности $(n=14)$ Преэклампсия $(n=31)$ \\
\hline Омфалит, гол. (\%): & $1(7,2)$ & $21(67,7)$ \\
всего & $0(0)$ & $12(38,7)$ \\
с тяжелым течением & $6(42,9)$ & $24(77,4)$ \\
Гастроэнтерит, гол. (\%): & $4(28,6)$ & $20(64,5)$ \\
всего & $8(57,1)$ & $31(100)$ \\
с тяжелым течением & $2(14,3)$ & $12(38,7)$ \\
Бронхит, гол. (\%) & $2(14,3)$ & $8(25,8)$ \\
Бронхопневмония, гол. (\%) & $0(0)$ & $3(9,7)$ \\
Анемия, гол. (\%): & & \\
всего & & \\
с тяжелым течением &
\end{tabular}

Развитие омфалита у телят было в значительной степени связано с состоянием эндогенной интоксикации, нарушениями эндокринной функции плаценты и фетоплацентарного кровообращения в перинатальный период. ROC-анализ показал, что коэффициент интоксикации, концентрация СМП и эстрадиола в сыворотке крови у коров, больных преэклампсией, могут служить предикторами развития омфалита у новорожденных телят. Эти показатели характеризовались хорошей диагностической ценностью (площадь под кривой AUC составила соответственно 0,747, 0,753 и 0,706), высокой чувствительностью (76,9 \% для всех показателей) и специфичностью (соответственно 52,9; 70,6 и 88,2 \%). Критические значения, отсекающие группу риска по развитию омфалита, составляли соответственно более 15,92, 0,412 усл. ед. и менее 83,6 пмоль/л.

Диагностическая ценность увеличения диаметра пупка (маркер перинатального нарушения фетоплацентарного кровообращения у коров) для прогнозирования развития омфалита у телят оценивалась как отличная $(\mathrm{AUC}=0,959)$ : чувствительность 84,6 \%, специфичность 100,0 \% при точке отсечения более 17,5 мм.

Развитие респираторных заболеваний у телят, полученных от коров с преэклампсией, было связано с состоянием эндогенной интоксикации, функциональной недостаточностью фетоплацентарной системы и циркуляторными нарушениями. Предикторами развития бронхопневмонии у новорожденных могут служить коэффициент интоксикации, содержание СМП и эстрадиола в сыворотке крови их матерей, а также диаметр пупка в первые 3 ч после рождения. Эти показатели характеризовались очень хорошей, хорошей и отличной диагностической ценностью (площадь под кривой AUC - соответственно 0,812; 0,782; 0,707 и 0,907), высокой чувствительностью $(85,7 ; 85,7 ; 77,8$ и 88,9 \%) и специфичностью $(59,1 ; 81,8$; 77,3 и 77,3 \%). Критические значения, отсекающие группу риска по развитию бронхопневмонии, - соответственно более 18,08 и 0,555 усл. ед., менее 71,2 пмоль/л и более 17,5 мм. Наибольшая диагностическая ценность для прогнозирования раннего (в 1-ю нед жизни) развития бронхита у телят была установлена для содержания эстрадиола (AUC $=0,729)$ и соотношения прогестерон/эстрадиол $(\mathrm{AUC}=0,750)$ в сыворотке крови их матерей: чувствительность - 70,8 и 54,2 \%, специфичность - 85,7 и 85,7 \%; 
критические значения, отсекающие группу риска по раннему развитию бронхита, - менее 116,8 пм/л и более 571,0:1.

Для прогнозирования тяжелого течения гастроэнтерита у телят наибольшую ценность имели концентрация эстрадиола $(\mathrm{AUC}=0,710)$ и соотношение прогестерон/эстрадиол $(\mathrm{AUC}=0,734)$ в сыворотке крови у коров, а также диаметр пупка у телят в первые 3 ч после рождения $(\mathrm{AUC}=0,782)$ : чувствительность - соответственно 77,8; 77,8 и 61,1\%, специфичность 77,$3 ; 71,4$ и 85,7 \%; критические значения, отсекающие группу риска по тяжелому течению гастроэнтерита, - менее 103,7 пмоль/л, более 413,9:1 и более 17,5 мм.

Развитие анемии у телят главным образом было связано с функциональной недостаточностью фетоплацентарной системы. ROC-анализ показал, что концентрация эстрадиола, ДГЭА-С, а также соотношение прогестерон/эстрадиол в сыворотке крови у коров, больных преэклампсией, могут служить предикторами тяжелого течения анемии (с содержанием гемоглобина в крови менее 70 г/л) у новорожденных телят. Эти показатели характеризовались хорошей диагностической ценностью (площадь под кривой AUC составила соответственно 0,782; 0,750 и 0,750), высокой чувствительностью (100,0 \% для всех показателей) и специфичностью $(61,3 ; 71,0$ и 51,6 \%); критические значения, отсекающие группу риска по тяжелому течению анемии у телят, - менее 78,0 пмоль/л, менее 0,229 мкмоль/л и более 510,1:1.

Хорошую диагностическую ценность $(\mathrm{AUC}=0,758)$ для прогнозирования развития анемии у новорожденных телят показало определение концентрации белка в моче коров, больных преэклампсией. При низкой чувствительности $(20,0$ \%) показатель характеризовался высокой специфичностью (94,7 \%); критическое значение, отсекающее группу риска по развитию анемии у телят, - более 2,0 г/л.

3. Масса тела телят, полученных от коров красно-пестрой породы с физиологическим течением беременности и преэклампсией (Новоусманский $\mathrm{p}-\mathrm{H}$, Воронежская обл., 2016 год)

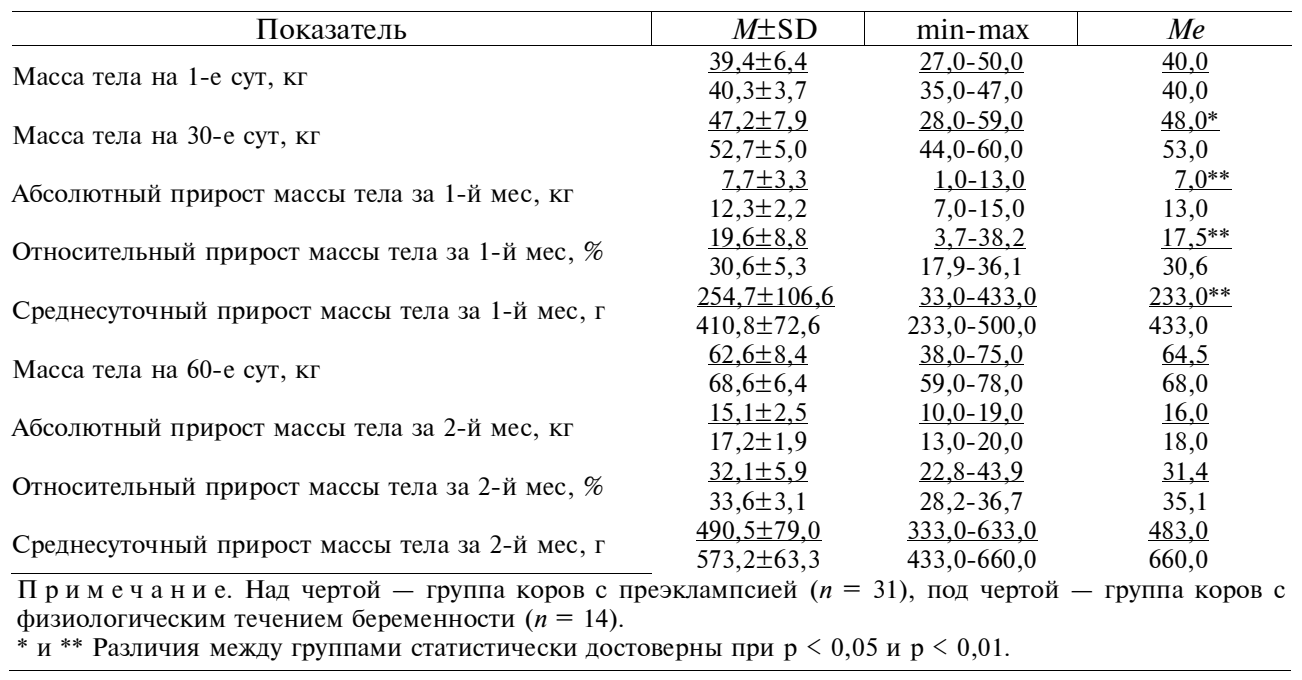

Достоверных различий по массе тела в 1-е сут жизни между I и II группами телят не обнаружили. На 30-е сут жизни масса телят, полученных от коров с преэклампсией, была на 9,4 \% ниже $(\mathrm{p}<0,05)$, чем у потомства коров с физиологическим течением беременности; к 60-м суткам различия по живой массе между группами телят нивелировались (табл. 3). 
Абсолютный прирост живой массы за 1-й мес жизни у телят от коров из I группы был на 46,2\% (p < 0,01) меньше, а относительный и среднесуточный прирост - на 42,8 \% (p < 0,01) и 46,2 \% (p < 0,01) меньше медианных значений у потомства животных из II группы. Корреляционный анализ выявил статистически значимую зависимость между среднесуточным приростом массы тела телят за 1-й мес жизни и показателями эндогенной интоксикации - коэффициентом интоксикации $\left(r_{S}=-0,79\right.$ при р $\left.<0,01\right)$ и содержанием среднемолекулярных пептидов в сыворотке крови $\left(r_{S}=-0,73\right.$ при р $<0,01)$, а также концентрацией эстрадиола $\left(r_{S}=+0,37\right.$ при $\left.\mathrm{p}<0,05\right)$ и соотношением прогестерон/эстрадиол $\left(r_{S}=-0,50\right.$ при $\left.\mathrm{p}<0,01\right)$ в сыворотке крови матерей, отражающим функциональное состояние фетоплацентарной системы. Обратная зависимость между среднесуточным приростом живой массы телят и показателями эндогенной интоксикации у коров, больных преэклампсией, - коэффициентом интоксикации $\left(r_{S}=-0,58\right.$ при $\mathrm{p}<0,01)$ и концентрацией среднемолекулярных пептидов в сыворотке крови $\left(r_{S}=-0,57\right.$ при р $\left.<0,01\right)$ сохранялась и во 2-й мес жизни.

Научный интерес к таким патологиям беременности, как функциональная недостаточность фетоплацентарной системы, внутриутробная задержка развития эмбриона и плода и преэклампсия, обусловлен не только их распространением среди продуктивных животных $(2,4,25)$, но и негативным влиянием на постнатальный рост и здоровье потомства $(9,13$, 16). Согласно концепции онтогенетической природы здоровья и болезней (developmental origins of health and disease, DOHaD), воздействие того или иного фактора в критическом периоде внутриутробного развития плода приводит к отдаленным последствиям в постнатальном онтогенезе (26-28). Ранее другие авторы указывали на пониженную жизнеспособность телят, полученных от коров с преэклампсией $(2,29,30)$, на их высокую заболеваемость омфалитом (12), желудочно-кишечными болезнями (31), респираторными болезнями $(18,32)$. Однако механизмы влияния преэклампсии у коров-матерей на морфофункциональный статус новорожденных телят до конца не раскрыты $(2,30)$.

По нашим данным, полученным в представленном исследовании, коровы с преэклампсией значительно различаются по концентрации белка в моче, показателям эндогенной интоксикации (ЭКА/ОКА, СМП, КИ) и содержанию стероидных гормонов (прогестерон, эстрадиол, ДГЭА-С) в сыворотке крови, что определяет прогноз развития неонатальных заболеваний у потомства. По результатам ROC-анализа, коэффициент интоксикации и содержание СМП в сыворотке крови коров, больных преэклампсией, могут служить предикторами развития омфалита и бронхопневмонии у новорожденных телят. Эти данные согласуются с более ранними сообщениями $(33,34)$ и свидетельствуют о тесной патогенетической связи омфалита и респираторных заболеваний у новорожденных телят. Известно, что СМП способны блокировать рецепторы клеток, загружать активные центры молекулы альбумина и конкурировать с регуляторными пептидами, нарушая процессы гуморальной регуляции, а также оказывать токсическое влияние на развивающийся плод $(23,25,35)$. Мы показали, что внутриутробная интоксикация негативно влияет на среднесуточный прирост живой массы у телят в первые 2 мес после рождения: у телят от матерей с физиологическим течением беременности этот показатель за 1-й мес жизни на 46,2\% (p < 0,01) превышал таковой в потомстве коров с преэклампсией. Обнаружена обратная зависимость между коэффициентом интоксикации у коров, больных преэклампсией, и среднесуточным приростом массы у полученных от них телят за $1-и ̆$ мес $\left(r_{S}=-0,79\right.$ при $\left.\mathrm{p}<0,01\right)$ и 2 -й мес 
$\left(r_{S}=-0,58\right.$ при р $\left.<0,01\right)$ жизни.

Определение содержания стероидных гормонов и их соотношения в сыворотке крови у глубокостельных коров позволяет выявлять функциональную недостаточность фетоплацентарной системы $(25,36)$ и прогнозировать развитие неонатальных заболеваний у потомства $(4,37)$. Для прогнозирования тяжелого течения гастроэнтерита и анемии у телят большую ценность показало определение концентрации эстрадиола и соотношения прогестерон/эстрадиол в сыворотке крови. Ранее K.L. Lavrijsen c coaвт. (38) в исследованиях in vitro продемонстрировали дозозависимый эффект прогестерона на эритропоэз у плода крупного рогатого скота, a V.A. Safonov c coавт. (37) показали возможность прогнозирования респираторных заболеваний у новорожденных телят по содержанию прогестерона, эстрадиола и их соотношению в сыворотке крови коров-матерей.

Протеинурия у коров на поздних сроках беременности свидетельствует о нарушении функциональной деятельности почек $(2,4,10,39)$. В нашей работе выявлена высокая специфичность определения концентрации белка в моче глубокостельных коров $(94,7$ \%) для прогнозирования развития анемии у телят (критическое значение - более 2,0 г/л); этот показатель может быть рекомендован для использования в условиях фермы.

Известно, что развитие преэклампсии у коров сопровождается нарушениями фетоплацентарного кровообращения, изменениями диаметра и структуры пупочных сосудов $(4,10-12)$. А. Золотарев с соавт. (12) установили, что увеличение диаметра пупка у основания брюшной стенки телят в первые 3 ч после рождения свыше 18,0 мм служит ретроспективным показателем нарушений фетоплацентарного кровообращения и указывает на высокую вероятность развития у них омфалита. В нашем исследовании диаметр пупка в первые 3 ч после рождения у телят от коров с физиологическим течением беременности и с преэклампсией достоверно $(\mathrm{p}<0,01)$ различался. Диагностическая значимость определения диаметра пупка для прогнозирования развития омфалита у телят оценивалась как отличная $(\mathrm{AUC}=0,959):$ чувствительность 84,6 \%, специфичность 100,0 \% при точке отсечения более 17,5 мм. Отметим, что зависимость между диаметром пупка у новорожденных телят и вероятностью развития у них гастроэнтерита, бронхопневмонии, а также тяжестью течения этих заболеваний, описанная в настоящем сообщении, обнаружена нами впервые и высокодостоверна ( $<<0,01)$. Результаты исследования свидетельствуют о том, что к развитию желудочно-кишечных и респираторных заболеваний у новорожденных телят предрасполагает не омфалит, а глубокие морфофункциональные изменения в системе мать-плацента-плод при преэклампсии, которые предшествуют развитию омфалита.

Итак, определение показателей эндогенной интоксикации (содержание среднемолекулярных пептидов, эффективная концентрация альбумина, коэффициент интоксикации), концентрации стероидных гормонов (прогестерона, эстрадиола и дегидроэпиандростерон-сульфата) в сыворотке крови и белка в моче у коров с симптомами преэклампсии за 25-32 сут до отела позволяет не только объективно оценивать состояние животных, но и прогнозировать развитие неонатальных заболеваний и прирост живой массы у их потомства. Измерение диаметра пупка у основания брюшной стенки в первые 3 ч после рождения должно быть включено в протокол обязательного клинического исследования телят, поскольку диаметр более 17,5 мм указывает на высокую вероятность развития омфалита (чувствительность 84,6 \%, специфичность 100,0 \%), тяжелого течения гастроэнтерита $(61,1$ и $85,7 \%)$ и бронхопневмонии $(88,9$ и 77,3 \%). Повышение жизне- 
способности и здоровья приплода у молочных коров невозможно без своевременной профилактики и терапии преэклампсии, которая должна включать коррекцию нарушений обмена веществ, снижение эндогенной интоксикации и оксидативного стресса, а также лечение экстрагенитальных заболеваний.

\author{
1ФГБНУ Всероссийский научно-исследовательский \\ ветеринарный институт патологии, фармакологии \\ и терапии, \\ 394087 Россия, г. Воронеж, ул. Ломоносова, 114-б, \\ e-mail: cherae@mail.ru,vnivipat@mail.ru $\bowtie$;
}

2ФГБУ Институт геохимии и аналитической

химии им. В.И. Вернадского РАН,

119991 Россия, г. Москва, ул. Косыгина, 19,

e-mail: geokhi.rus@relcom.ru

Sel'skokhozyaistvennaya biologiya [Agricultural Biology], 2019, V. 54, № 2, pp. 246-258

Поступила в редакцию
1 октября 2018 года

\title{
MULTIPLE EFFECTS OF PREECLAMPSIA IN COWS ON POSTNATAL GROWTH AND HEALTH OF OFFSPRING
}

\author{
A.E. Chernitskiy 1 , S.V. Shabunin'1, V.A. Safonov ${ }^{2}$
}

\begin{abstract}
${ }^{1}$ All-Russian Research Veterinary Institute of Pathology, Pharmacology and Therapy, 114-b, ul. Lomonosova, Voronezh,394087 Russia, e-mail vnivipat@mail.ru ( $\square$ corresponding author), cherae@mail.ru;

${ }^{2}$ Vernadskii Institute of Geochemistry and Analytical Chemistry RAS, Federal Agency of Scientific Organizations, 19, ul. Kosygina, Moscow, 119991 Russia, e-mail geokhi.rus@relcom.ru

ORCID:
\end{abstract}

Chernitskiy A.E. orcid.org/0000-0001-8953-687X

Shabunin S.V. orcid.org/0000-0002-2689-6998

The authors declare no conflict of interests

Received October 1, 2018

Safonov V.A. orcid.org/0000-0002-5040-6178

doi: 10.15389 /agrobiology.2019.2.246eng

\section{Abstract}

Scientific interest in such pathologies of pregnancy as functional deficiency of the fetoplacental system, intrauterine growth retardation of embryo and fetus, and preeclampsia (gestosis), is caused not only by their wide spread among productive animals, but also by negative impact on postnatal growth and the health of offspring. The influence of a preeclampsia on incidence of newborn calves of anemia, an omphalitis, inflammatory diseases of gastrointestinal and respiratory tracts and also intensity of growth in the first two months of life was studied on red-motley cows in 2016 in the conditions of a large dairy complex (Voronezhpishcheprodukt Co Ltd, Novousmansky Rregion, Voronezh Province). Total of 45 cows (Bos taurus taurus) with a gestation period of 248-255 days were examined, including 31 with clinical signs of preeclampsia and 14 with the physiological course of pregnancy, and calves obtained from them $(n=45)$. The cows were assessed for clinical signs of preeclampsia (pathological swelling of mammary gland, ventral abdominal wall, dewlap, pelvic extremities, arterial hypertension and proteinuria), the blood concentrations of progesterone, estradiol and dehydroepiandrosterone sulfate (DHEA-S) were determined, the endogenous intoxication features were examined, i.e. concentration of middle molecular peptides (MMP), effective (ECA) and total (TCA) serum albumin concentration, the toxicity index TI = (TCA/ECA) -1 and the intoxication coefficient $\mathrm{IC}=(\mathrm{MMP} / \mathrm{ECA}) \times 1000$ were calculated. Within 1-3 hours after birth, the diameter of the calves' navel was measured; an increase in the diameter of the navel of more than 18.0 $\mathrm{mm}$ was considered as a retrospective indicator of the fetoplacental blood circulation disorder. On day 1, day 30 and day 60 the calves' bodyweight was measured; the absolute, relative and average daily weight gain for the first and second months of life was calculated. During the first 60 days of life, the calves underwent constant clinical observation, the incidence of anemia, an omphalitis, gastroenteritis, bronchitis, bronchopneumonia and severity of disease course were considered. Frequency of anemia cases in calves from mother cows with preeclampsia was 1.80 -fold, of omphalitis 9.40 fold, of gastroenteritis 1.80-fold, of bronchitis 1.75-fold, and of bronchopneumonia 2.71-fild as compared to animals from cows with the physiological course of pregnancy. For the first month of life, an average daily bodyweight gain of the calves received from the cows suffered from a preeclampsia was $46.2 \%$ ( $p<0.01$ ) less than that of offspring of healthy cows. We revealed significant individual differences in the protein concentration in urine, endogenous intoxication parameters (ECA/TCA, MMP, IC) and the blood content of steroid hormones (progesterone, estradiol, DHEA-S) among the cows with the symptoms of preeclampsia. An inverse relationship was established between the rate of intoxication in cows with preeclampsia and the average daily body- 
weight gain in their calves during the first month $\left(r_{S}=-0.79, \mathrm{p}<0.01\right)$ and the second $\left(r_{S}=-0.58\right.$, $\mathrm{p}<0.01)$ month of life. As proteinuria in cows increases, the probability of omphalitis progression $\left(r_{\tau-K}=+0.32, \mathrm{p}<0.05\right)$ and anemia $\left(r_{\tau-K}=+0.33, \mathrm{p}<0.05\right)$ of calves increases too. Statistically significant links are found between accumulation of MMP in blood of cows suffering from preeclampsia, and probability of omphalitis $\left(r_{\tau-K}=+0.36, \mathrm{p}<0.01\right)$ and bronchopneumonia $\left(r_{\tau-K}=+0.35, \mathrm{p}<0.05\right)$ progression in their offspring and also between coefficient of intoxication and probability of progression of these diseases (with $\tau$-Kendall's coefficients $+0.35,+0.35$ and +0.38 respectively at $\mathrm{p}<0.05)$. The functional disorder of fetoplacental system is associated with progression of omphalitis $\left(r_{\tau-K}=+0.33, \mathrm{p}<0.05\right)$, gastroenteritis $\left(r_{\tau-K}=+0.49, \mathrm{p}<0.01\right)$ and also early (within the first week of life) manifestation of bronchitis $\left(r_{t-K}=+0.48, \mathrm{p}<0.01\right)$ in calves, and fetoplacental blood circulation disorder is associated with gastroenteritis $\left(r_{\tau-K}=+0.77, \mathrm{p}<0.01\right)$ and bronchopneumonia $\left(r_{t-K}=+0.75, \mathrm{p}<0.01\right)$. ROC-analysis showed that the factor of intoxication and the content of MMP in the blood serum of cows suffering from preeclampsia may serve as predictors of omphalitis and bronchopneumonia progression in newborn calves. Blood concentration of estradiol and the ratio of progesterone/estradiol in mother cows are valuable indicators to predict a severe course of gastroenteritis and anemia in their calves. High specificity $(94.7 \%)$ for predicting anemia progression for newborn calves is detected for proteinuria of more than $2.0 \mathrm{~g} / \mathrm{l}$.

Keywords: preeclampsia, pregnancy, Bos taurus taurus, cows, calves, arterial hypertension, proteinuria, anemia, omphalitis, gastroenteritis, respiratory diseases, average daily bodyweight gain, ROC-analysis.

\section{REFEREN C ES}

1. Nezhdanov A.G., Retskii M.I., Alekhin Yu.N., Safonov V.A., Shushlebin V.I., Papin N.E., Brekhov T.P., Shishkina E.V. Clinico-hematologic and biochemical status of cows at gestosis. Sel'skokhozyaistvennaya Biologiya [Agricultural Biology], 2010, 4: 118-123 (in Engl.).

2. Shabunin S.V., Alekhin Yu.N., Nezhdanov A.G. Veterinariya, 2015, 1: 3-10 (in Russ.).

3. Rook J.S. Pregnancy toxemia of ewes, does, and beef cows. Veterinary Clinics of North America: Food Animal Practice, 2000, 16(2): 293-317 (doi: 10.1016/S0749-0720(15)30107-9).

4. Kolchina A.F. Bolezni beremennykh i perinatal'naya patologiya u zhivotnykh [Diseases of pregnant animals and perinatal pathology]. Ekaterinburg, 1999 (in Russ.).

5. Avdeenko V.S., Donnik I.M., Loretts O.G., Babukhin S.N., Rykhlov A.S., Molchanov A.V. Agrarnyi vestnik Urala, 2016, 8(150): 4-9 (in Russ.).

6. Sircar M., Thadhani R., Karumanchi S.A. Pathogenesis of preeclampsia. Current Opinion in Nephrology and Hypertension, 2015, 24(2): 131-138 (doi: 10.1097/MNH.0000000000000105).

7. Armaly Z., Jadaon J.E., Jabbour A., Abassi Z.A. Preeclampsia: novel mechanisms and potential therapeutic approaches. Frontiers in Physiology, 2018, 9: 973 (doi: 10.3389/fphys.2018.00973).

8. Robillard P.Y., Dekker G., Chaouat G., Le Bouteiller P., Scioscia M., Hulsey T.C. Preeclampsia and the 20th century: «Le siècle des Lumières». Pregnancy Hypertension, 2018, 13: 107-109 (doi: 10.1016/j.preghy.2018.05.013).

9. Granger J.P., George E.M., Roberts J.M. Chapter 10 - Animal models for investigating pathophysiological mechanisms of preeclampsia. In: Chesley's hypertensive disorders in pregnancy (Fourth edition). R.N. Taylor, J.M. Roberts, F.G. Cunningham, M.D. Lindheimer (eds.). Academic Press, San Diego, 2015: 209-220 (doi: 10.1016/B978-0-12-407866-6.00010-9).

10. Nezhdanov A.G., Kochura M.N., Misailov V.D., Shakhov A.G., Retskii M.I., Bliznetsova G.N., Alekhin Yu.N., Shushlebin V.I., Brekhov T.P. Mezhdunarodnyi vestnik veterinarii, 2010, 1: 12-17 (in Russ.).

11. Rodin P.V., Avdeenko V.S. Voprosy normativno-pravovogo regulirovaniya v veterinarii, 2015, 2: 233-235 (in Russ.).

12. Zolotarev A., Shakhov A. Omfalit novorozhdennykh telyat. Etiologiya, diagnostika, profilaktika, lechenie. LAP LAMBERT Academic Publishing GmbH \& Co. KG, Saarbrücken, 2012.

13. O’Dowd R., Kent J.C., Moseley J.M., Wlodek M.E. Effects of uteroplacental insufficiency and reducing litter size on maternal mammary function and postnatal offspring growth. American Journal of Physiology Regulatory, Integrative and Comparative Physiology, 2008, 294(2): R539R548 (doi: 10.1152/ajpregu.00628.2007).

14. Ginther O.J., Douglas R.H. The outcome of twin pregnancies in mares. Theriogenology, 1982, 18(2): 237-242 (doi: 10.1016/0093-691X(82)90108-X).

15. Thornbury J.C., Sibbons P.D., van Velzen D., Trickey R., Spitz L. Histological investigations into the relationship between low-birth-weight and spontaneous bowel damage in the neonatal piglet. Pediatric Pathology, 1993, 13(1): 59-69 (doi: 10.3109/15513819309048193).

16. Mestan K.K., Steinhorn R.H. Fetal origins of neonatal lung disease: understanding the pathogenesis of bronchopulmonary dysplasia. American Journal of Physiology Lung Cellular and Molecular Physiology, 2011, 301(6): L858-L859 (doi: 10.1152/ajplung.00314.2011).

17. Rozance P.J., Seedorf G.J., Brown A., Roe G., O’Meara M.C., Gien J., Tang J.-R., Abman S.H. 
Intrauterine growth restriction decreases pulmonary alveolar and vessel growth and causes pulmonary artery endothelial cell dysfunction in vitro in fetal sheep. American Journal of Physiology Lung Cellular and Molecular Physiology, 2011, 301(6): L860-L871 (doi: 10.1152/ajplung.00197.2011).

18. Zolotarev A.I., Chernitskii A.E. V sbornike: Aktual'nye problemy veterinarnogo akusherstva $i$ reproduktsii zhivotnykh [In: Actual aspects of veterinary obstetrics and animal reproduction]. Gorki, 2013: 262-266 (in Russ.).

19. Shakhov A.G., Sashnina L.Yu., Alekhin Yu.N., Prigorodova O.V. Vestnik Rossiiskoi akademii sel'skokhozyaistvennykh nauk, 2014, 6: 69-71 (in Russ.).

20. Chernitskii A.E., Sidel'nikova V.I., Zolotarev A.I., Retskii M.I. Sposob neinvazivnoi ekspressdiagnostiki vospalitel'nogo protsessa v kishechnike u telyat. Pat. 2552333 (RF), MPK G01N 33/48, G01N 33/50. Gosudarstvennoe nauchnoe uchrezhdenie Vserossiiskii nauchno-issledovatel'skii veterinarnyi institut patologii, farmakologii i terapii Rossiiskoi akademii sel'skokhozyaistvennykh nauk (RF). № 2014124675/15. Zayavl. 17.06.2014. Opubl. 10.06.2015. Byul. № 16 (doi: 10.13140/RG.2.1.4283.0569) [Method of non-invasive rapid diagnosis of inflammation in calves intestines. Pat 2552333 (RF), IPC G01N 33/48, G01N 33/50. All-Russian Research Veterinary Institute of Pathology, Pharmacology and Therapy RAAS (RF). No. 2014124675/15. Appl. 17.06.2014. Publ. 10.06.2015. Bul. No. 16] (in Russ.).

21. McGuirk S.M. Disease management of dairy calves and heifers. Veterinary Clinics of North America: Food Animal Practice, 2008, 24(1): 139-153 (doi: 10.1016/j.cvfa.2007.10.003).

22. Chernitskii A.E., Sidel'nikova V.I., Retskii M.I. Veterinariya, 2014, 4: $56-58$ (in Russ.).

23. Sidel'nikova V.I., Chernitskii A.E., Retskii M.I. Endogenous intoxication and inflammation: reaction sequence and informativity of the markers (review). Sel'skokhozyaistvennaya Biologiya [Agricultural Biology], 2015, 50(2): 152-161 (doi: 10.15389/agrobiology.2015.2.152eng).

24. DeLong E.R., DeLong D.M., Clarke-Pearson D.L. Comparing the areas under two or more correlated receiver operating characteristic curves: a nonparametric approach. Biometrics, 1988, 44(3): 837-845.

25. Nezhdanov A., Shabunin S., Mikhalev V., Klimov N., Chernitskiy A. Endocrine and metabolic mechanisms of embryo and fetal intrauterine growth retardation in dairy cows. Turkish Journal of Veterinary and Animal Sciences, 2014, 38(6): 675-680 (doi: 10.3906/vet-1405-12).

26. Langley-Evans S.C. Developmental programming of health and disease. Proceedings of the $\mathrm{Nu}$ trition Society, 2006, 65(1): 97-105 (doi: 10.1079/PNS2005478).

27. Gallo L.A., Tran M., Moritz K.M., Wlodek M.E. Developmental programming: variations in early growth and adult disease. Clinical and Experimental Pharmacology and Physiology, 2013, 40(11): 795-802 (doi: 10.1111/1440-1681.12092).

28. Fukuoka H. DOHaD (developmental origins of health and disease) and birth cohort research. Journal of Nutritional Science and Vitaminology, 2015, 61(S): S2-S4 (doi: 10.3177/jnsv.61.S2).

29. Sorokovoi V.S. Veterinariya, 1994, 10: 37-41 (in Russ.).

30. Krishtoforova B.V., Gavrilin P.N. Visnik Bilotserivskogo dzerzhavnogo agrarnogo universitetu, 1998, 5(1): 87-90 (in Russ.).

31. Misailov V.D., Nezhdanov A.G., Kotsarev V.N., Kochura M.N., Mikhalev V.I., Skryl'nikov O.N., Suleimanov S.M., Zolotarev A.I. Sel'skokhozyaistvennye zhivotnye, 2007, spetsial'nyi vypusk: 13 (in Russ.).

32. Shabunin S.V., Shakhov A.G., Chernitskii A.E., Zolotarev A.I., Retskii M.I. Veterinariya, 2015, 5: 3-13 (in Russ.).

33. Kalaeva E.A., Kalaev V.N., Alkhamed M., Chernitskii A.E., Kaverin N.N. Acta Naturae (russkoyazychnaya versiya), 2017, 9(S): 64 (in Russ.).

34. Safonov V.A., Shabunin S.V., Chernitskiy A.E. Endogenous intoxication indices in cows with preeclampsia as predictors of respiratory diseases development in their offspring. Animal Reproduction, 2019, 16(1): 112 (doi: 10.13140/RG.2.2.27955.48169).

35. Britvina K.V., Vasil'eva Z.V., Kitsenko E.A., Mitichkin A.E., Apresyan S.V. Vestnik Rossiiskogo universiteta druzhby narodov. Seriya: Meditsina, 2013, S5: 16-21 (in Russ.).

36. Vlasov S.A. Fetoplatsentarnaya nedostatochnost' u korov (patogenez, diagnostika, profilaktika) [Placental insufficiency in cows (pathogenesis, diagnosis, prophylactic)]. Voronezh, 2000 (in Russ.).

37. Safonov V.A., Chernitskiy A.E. Serum concentration of sex steroids in down-calving cows as predictors of the respiratory diseases progression among their posterity. Animal Reproduction, 2018, 15(S1): 1069 (doi: 10.13140/RG.2.2.19779.66083).

38. Lavrijsen K.L., Verwilghen R.L. The effect of progesterone on hemoglobin synthesis in suspension cultures of fetal erythroid cells from calf liver. Biochimica et Biophysica Acta (BBA) - Molecular Cell Research, 1984, 803(4): 290-301 (doi: 10.1016/0167-4889(84)90120-4).

39. Hussein W., Lafayette R.A. Renal function in normal and disordered pregnancy. Current Opinion in Nephrology and Hypertension, 2014, 23(1): 46-53 (doi: 10.1097/01.mnh.0000436545.94132.52). 